\title{
UNDERSTANDING INCLUSIVE DESIGN EDUCATION
}

\author{
Wilson, Nicky; Thomson, Avril; Thomson, Angus; Holliman, Alexander 'Freddie' \\ University of Strathclyde
}

\begin{abstract}
There is a need for responsible engineering design to accommodate the diverse user requirements that come with the global phenomenon of population ageing. Inclusive design can address these diverse requirements through the consideration of a wide diversity of user needs within the design process. However, uptake of inclusive design in industry is limited, with designer awareness of the approach and its associated methods and tools noted as barriers to its uptake. This research aims to understand the current approach to inclusive design education within UK Higher Education Institutions, utilising interviews with design educators and a student survey. The study concluded that teaching of inclusive design varied between institutions with conflicting responses from academics and students relating to the methodologies taught. This study recommends that greater transparency should be encouraged between institutions to encourage the development of a cohesive inclusive design education strategy, in addition to the development of a framework to aid the implementation of appropriate inclusive methods and tools within the design process.
\end{abstract}

Keywords: Inclusive design, Design education, Design methods, Design process, Design practice

Contact:

Wilson, Nicky

University of Strathclyde

Design, Manufacture and Engineering Management

United Kingdom

nicky.wilson.90@outlook.com

Cite this article: Wilson, N., Thomson, A., Thomson, A., Holliman, A. 'Freddie'. (2019) 'Understanding Inclusive Design Education', in Proceedings of the 22nd International Conference on Engineering Design (ICED19), Delft, The Netherlands, 5-8 August 2019. DOI:10.1017/dsi.2019.66 


\section{INTRODUCTION}

Population ageing is a global issue that is set to become one of the most significant social transformations of the twenty first century (United Nations, 2015) with the UN predicting the number of people aged over 60 will grow by $54 \%$ by 2030 (United Nations, 2015). Additionally, the World Health Organisation (2011) report over one billion people live with some form of disability. This raises unprecedented global challenges including increased expenditure on health care, labour force shortages and income security (Bloom et al., 2015) with designers responsible for designing functional and accessible products for a growing, diverse market.

The Design Council defines inclusive design (ID) as "a general approach to designing in which designers ensure their products and services address the needs of the widest population possible, irrespective of age and ability" (Design Council, 2008). This philosophy includes all users within the engineering design process to ensure products and services are usable and accessible to as wide a range of the population as possible. With the diverse capabilities resulting from disability and population ageing, there is an immediate opportunity ID can address.

However, awareness of ID in industry is low (Carse et al., 2010). Sims (2003) identified that while $72 \%$ of designers were aware of ID, Goodman-Deane et al. (2010) found that many designers did not implement ID routinely. To address the challenges associated with population ageing, it is vital that designers are equipped with the toolset and knowledge to accommodate these diverse user needs. This research aims to understand the current approach to ID education within UK Higher Education Institutions.

\section{BACKGROUND}

Inclusive design (ID) looks to provide designers with a more accurate understanding of the requirements of different user groups, with the aim of driving informed decisions throughout the engineering design process (Waller et al., 2015). The primary objective of ID is to create equality within society through the eradication of social exclusion (Clarkson \& Coleman, 2015). Within this paper the term ID covers similar approaches such as universal design and design for all. More specific approaches such as accessible design are not covered in this paper, although many of the recommendations made here will be relevant to these approaches.

ID is an approach that can tackle the diverse population needs that come with disability and ageing, such as declines in physical and cognitive capabilities (Bouma, 2013) that make it difficult for older users to carry out simultaneous tasks. Heterogeneity also increases with age - as the population gets older, the needs and capabilities of users becomes more diverse (Johnson et al., 2010). ID aims to make products more usable by the wider population (Dong et al., 2004a), helping individuals become less reliant on healthcare and social services (Cremers et al., 2014) and maintaining independence for longer.

ID relies heavily on the collection of user information to justify design decisions (Keates et al., 2000). Involvement of the end user throughout the design process drives informed decision making (Vavik \& Keitsch, 2010) and ensures their needs are incorporated within the design process, making the designer less reliant on their own perception of the problem. An ID approach benefits the design process as a whole, with additional time and resources in the early stages of the process ensuring user requirements are satisfied and minimising the need for costly design alterations later in the process (Waller et al., 2015).

Research into ID over the last 20 years has produced a range of ID methods and tools which allow designers to experience and/or design for diverse capabilities. Simulation gloves and glasses (University of Cambridge, 2013) allow designers to empathise with users and design more effectively towards their needs. Tools like the Inclusive Design Toolkit educate designers on how to apply an ID approach, while the Exclusion Calculator offers a quantitative tool to assess levels of capability required to use a product. The benefits of ID are also well documented and go beyond minimising design exclusion - users become more independent and are able to integrate themselves more easily with society (Vavik \& Keitsch, 2010). This ability to become self-sufficient reduces the assistive care required from health authorities. Designing inclusively also expands the target market for companies (Dong et al., 2004b) with ID improving user experience for able-bodies users. An ID approach also ensures user needs are satisfied early in the design process, minimising the need for costly alterations and rework later in the process (Waller et al., 2015). 
Despite the benefits of ID, awareness within industry remains low (Carse et al., 2010) and few companies currently include it within their design activities (Wilson, 2017). Previous work (Wilson et al., 2017) has focused on ID barriers associated with the client. However, Langdon et al. (2015) identified that lack of designer experience in the implementation of ID methods and tools is a significant factor limiting the uptake of ID in industry. This is further reinforced by Dong et al. (2004b) who found one of the major limitations to the use of user-centred design principles was a "lack of knowledge and techniques". The same conclusion was reached by Cremers et al. (2013), stating that "awareness of inclusive design is still lacking", and that "unfamiliarity with design seems to be a barrier for participation". In this paper, we focus on those barriers associated with designer and their experience in applying an ID approach.

Implementation of ID is reliant on the education of designers, as they are responsible for its application and expansion in an industrial context (Dong, 2015). However, despite the well documented social and commercial advantages of ID, universities which teach ID remain scarce (Vavik, 2011) raising questions of how prepared designers are to implement ID in industry. Education is perceived as the best way to raise the profile of ID, with increased educational participation being more influential than changes to legislation (Carter, 2014). However, the rarity of ID within educational institutions has resulted in limited literature surrounding the teaching strategy and methods. To understand designer awareness of ID methods and tools and their implementation within the design process, this research focused on the education of product design engineers in Higher Education Institutions through the first research question: RQ 1 - How is inclusive design taught to engineering design students?

Approaches to ID education include detailing the key principles of ID (MacDonald, 2006) followed by class exercises and projects to encourage students to utilise ID methods and tools in practice (Herriott \& Jensen, 2013). However, there are difficulties in educating designers in ID, which are summarised by Dong (2010):

- Large class sizes make the teaching of the fundamental ID principles difficult to express and practice.

- Logistical difficulties in achieving the multi-disciplinary teams advised for ID activities.

- The requirement for ethics assessments within design classes makes the implementation of user interaction activities more challenging.

- A lack of successful ID case studies with which to convey the basic principles of the approach.

- Distinguishing the difference between ID and design for special needs within a design program.

- Encouraging students to consider all of their senses when designing inclusively, rather than concentrating solely on physical aspects.

The literature reports on success experienced in the educational approach to ID (Dong, 2010). However, there are clear gaps in the current knowledge base of engineering design students with scope remaining for development and further research. ID needs to be communicated more effectively to designers and knowledge of ID methods and tools should be more widely applied. Despite the number of ID methods and tools available, it is apparent that these need to be delivered and communicated more effectively to designers. User information is at the centre of the ID process and it is essential that designers are able to identify the product use contexts and appropriate user activities (Reed \& Monk, 2011). ID methods and tools help designers to achieve a user centred solution whilst the iterative design process supports them in the analysis and utilisation of user information. However, the lack of awareness of ID amongst the designer population suggests that education of designers surrounding ID could be improved. This research argues that education should be one of the primary focuses for future ID development and raises the second research question addressed in this paper: RQ2 - Would a structured approach to inclusive design benefit the education of engineering design students?

\section{RESEARCH APPROACH}

This research aims to understand the current approach to inclusive design education within UK Higher Education Institutions by addressing the following research questions:

RQ1 - How is inclusive design taught to engineering design students?

RQ2 - Would a structured approach to inclusive design benefit the education of engineering design students? 
The research utilised interviews with design educators at universities across the UK, in addition to a survey completed by engineering design students regarding their education experience with ID. The research approach is summarised in Figure 1.

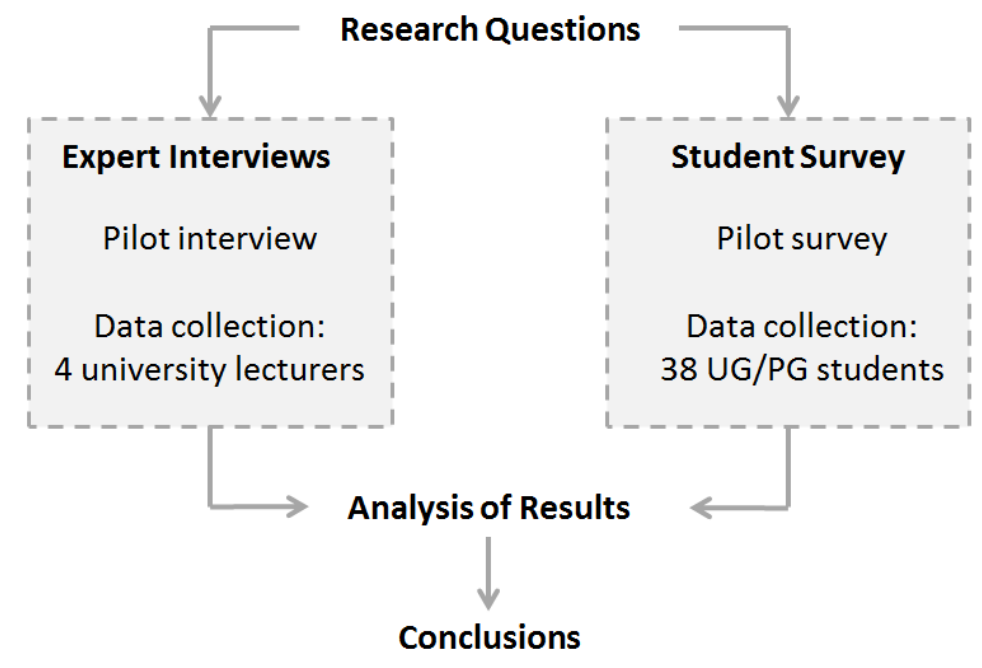

Figure 1: Research approach

\subsection{Expert interviews}

Four semi-structured interviews were conducted with design educators with at least ten years' experience lecturing in the field of ID education to gather their interpretation of the current educational practices. All lecturers currently teach ID modules in leading engineering design institutions across the UK and all hold an established body of published literature on the subject. The interviews identified how ID is currently taught to engineering design students and how this approach to be better facilitated. The following questions were asked:

1. What modules (and class size) is ID taught within?

2. What resources are used when teaching ID?

3. What teaching methods/approaches do you use to teach ID?

4. How effective do you consider your current approach to teaching ID?

5. What improvements would you make to your current ID teaching approach?

6. Do you structure your teaching using an ID framework or process? If not, would one be of use?

7. Do you believe a more structured approach to teaching ID would enhance ID practice in industry?

Table 1 summaries the profiles of those interviewed. The interviews were piloted with minor changes made to timings and the flow of questioning. Interviews lasted approximately 20 minutes and were recorded and fully transcribed, with key themes identified in the data using navigable tables which enabled the generation of useful insights (Easterby-Smith et al., 2012).

Table 1: Interviewee profiles

\begin{tabular}{c|c|c|c} 
Participant & Occupation & Educational Institution & Interview Style \\
\hline Participant A & Lecturer & Institution A & Face-to-face \\
Participant B & Lecturer & Institution B & Face-to-face \\
Participant C & Lecturer & Institution C & Phone \\
Participant D & $\begin{array}{c}\text { Head of School of Design } \\
\text { Engineering }\end{array}$ & Institution D & Phone
\end{tabular}

\subsection{Student survey}

The survey aimed to understand what material had been communicated to engineering design students, their perception of the learning experience and whether a more structured approach to ID would facilitate the learning experience of the approach. 
The following questions were asked:

1. Throughout your design education, how much time has been spent on ID?

2. How would you rate your understanding of the benefits of ID for individuals and companies?

3. How would you rate your understanding of the barriers to ID?

4. How would you rate your understanding of the basic principles of ID (methods, processes, etc.)?

5. Which of the following ID methods and tools are you familiar with?

6. Do you feel ID methods and tools were introduced effectively so you understood the needs of diverse users?

7. Have real-world case studies been used to demonstrate the application of ID methods and tools?

8. Have you been taught a design process that specifically concerned ID?

The survey was generated using Qualitrics and distributed to students electronically. The participants selected for the survey consisted of both undergraduate and postgraduate engineering design students within the Institution B. The survey was distributed to 4th and 5th year undergraduate and postgraduate students to ensure the respondents possessed an appropriate depth of design knowledge. The survey was distributed to around 100 engineering design students with 38 students responding.

The information gathered through the interviews and survey responses was analysed and key themes identified in relation to the research questions. The survey provided numerical data which was compared and contrasted with the responses to the semi-structured interview. The findings were clearly displayed through various infographics, and where applicable the information was interpreted as a Likert Scale to strengthen the analysis.

\section{RESULTS}

\subsection{Expert interviews}

In response to RQ1, it was observed that three of the four universities involved in the interview do not teach ID as a specific module, but instead include it as part of multiple user-centred design classes throughout the curriculum - "ID is simply considered good design and therefore not taught as a specific module" (participant C). For the fourth university, participant D reported, "ID is taught as an explicit topic through four individual modules, where the complete module content is based on ID principles". Class sizes varied from 20 and 120 students both within and between universities.

A range of physical and online ID resources were available from each university and utilised to facilitate the learning and application of ID methods, as summarised in Table 2. Institutions delivered a mix of empathetic methods and tools, utilising both physical and online resources for a mixed approach. The teaching strategy for ID was similar across all four institutions, consisting of short lectures detailing the key principles of ID followed by class exercises and projects to encourage students to utilise ID methods and tools in practice. This format is largely consistent with that discussed in the literature (MacDonald, 2006; Herriott \& Jensen, 2013), however clear variation was identified regarding the content of lectures - "one lecture will discuss the social, political, economic and legal factors surrounding ID" (participant B), "lectures detail case studies of positive examples of ID" (participant D).

Table 2: ID methods and tools taught across universities

\begin{tabular}{c|c} 
Participant & ID methods and tools taught \\
\hline Participant A & $\begin{array}{r}\text { Cambridge engineering gloves, simulation glasses and sensory } \\
\text { bag. Limited use of Exclusion Calculator, ethnography, } \\
\text { participation and observation. }\end{array}$ \\
Participant B & $\begin{array}{r}\text { Inclusive Design Toolkit, students advised of online resources, } \\
\text { impairment glasses, gloves, "third age suit". }\end{array}$ \\
Participant C & Cambridge engineering gloves and simulation glasses. \\
Participant D & Personas, occlusion devices, constraint devices, Exclusion \\
Calculator.
\end{tabular}


In response to how effective they felt their teaching approach to ID was, two participants believed their approach was effective, while two did not - "students leave with an understanding of ID but they may not be able to apply the design methods accurately" (participant B). However, all four participants felt there was a need to improve how ID is delivered to students - "this is an ever developing domain and more effective approaches to communicating ID principles need to be developed to progress understanding" (participant D).

When asked if they could suggest improvements to their ID teaching approach, participants stated they felt ID should play a more prominent role within all design classes - "every design class should have an element of ID embedded within it. If we teach ID as a separate module it creates an ideology that ID is aimed specifically at older and disabled users" (participant C). One participant reported "we could look into successes and failures to see what other institutions are trying and possibly build upon them" (participant A).

In response RQ2, all participants stated they believed this would contribute little benefit to the educational experience for students. None of those interviewed utilised a specific ID process or framework at the time of interview, but used ID methods and tools at various stages within standard design processes. It was highlighted that one design process is unlikely to suit every project and that a design process should be specified for a particular project based on the parameters and desired outcome. Instead students should be presented with a variety of generic design processes with the most suitable being selected for each project. The reasons provided for this were as follows:

- One design process is unlikely to be suitable for all design projects and therefore it is beneficial to have a selection.

- ID is considered to be a design philosophy as opposed to a separate design process.

- A more structured design process may be too complex for first and second year undergraduate students.

- Educational tools should remain constant with those used in industry and therefore introducing a new process or framework may cause confusion.

However, two participants stated there was a need to provide some structure within the design process to indicate where ID methods and tools should be used - e.g. "a way of showing the standard design process with signposts throughout to indicate when and where ID elements should be used would be useful" (participant B).

\subsection{Student survey}

Of the thirty-eight students surveyed, 93\% were undergraduate students, while the remaining $7 \%$ were post-graduate. Almost half (47\%) of respondents reported having spent less than four hours of their total design education learning about ID, with only $7 \%$ reported having spent longer than 10 hours.

Students generally believed they had a good understanding of the benefits of ID, with $24 \%$ rating themselves as adequate, $50 \%$ as good and $9 \%$ as very good. Only $17 \%$ believed their understanding was poor. In response to their understanding of the barriers to ID, they rated themselves as very poor $(3 \%)$, poor $(22 \%)$, adequate $(43 \%)$ and good $(32 \%)$. In response to understanding of ID methods and tools they rated themselves as very poor (4\%), poor (27\%), adequate (43\%) and good (26\%).

When asked on which of the following ID methods and tools they were familiar with, personas, observations and interviews were the most common response, as shown in Figure 2. Interestingly these can be thought of as more generic user centred design methods. Less common methods included the Cambridge simulation glasses and gloves, the Exclusion Calculator and Universal Design guidelines, all of which are specifically ID methods and tools.

In response to how effectively ID methods and tools were delivered to students, $68 \%$ believed current methods were effective. $84 \%$ of students had experience with class exercises or case studies relating to ID. 68\% respondents stated this was beneficial to their learning, however dispersion of responses highlighted there is still potential for improvement. $43 \%$ of students felt they had been taught a specific ID process, while $79 \%$ felt that a more structured approach to delivering ID methods and tools would be beneficial. 


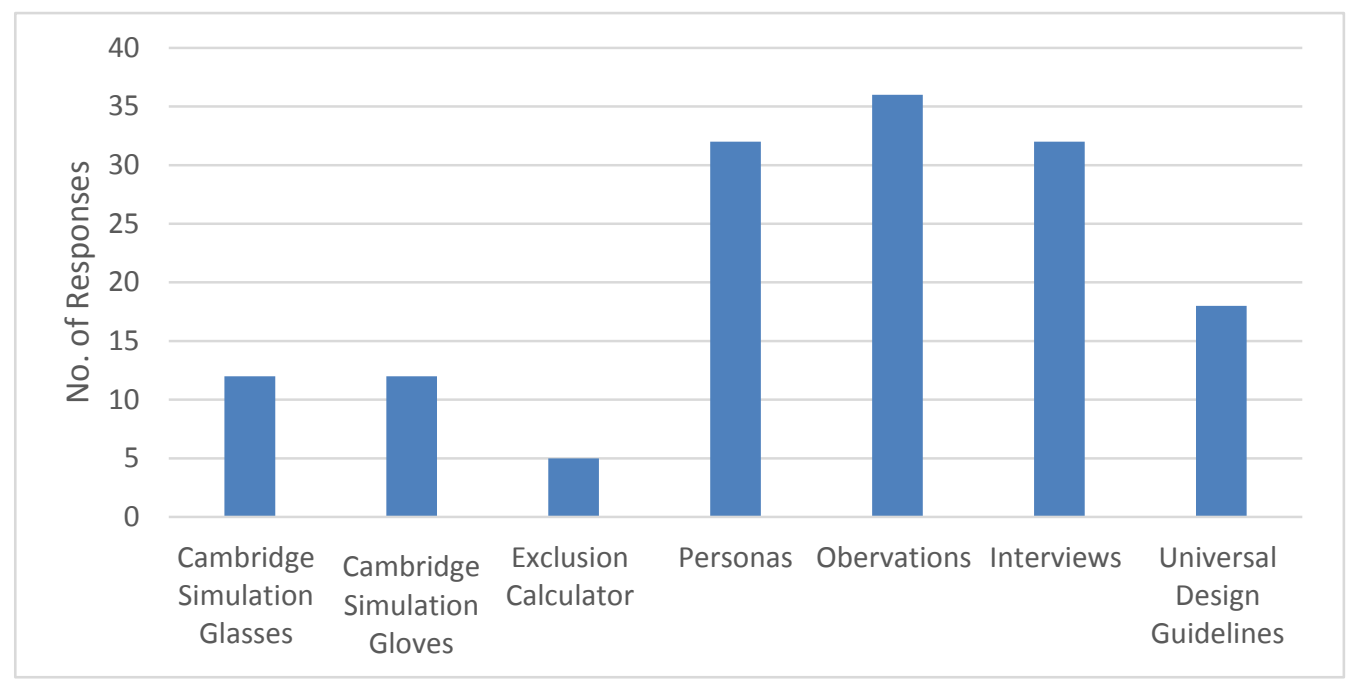

Figure 2: Research methods and tool utilisation

\section{DIscussion}

This section will discuss the research results in relation to RQ1 and RQ2.

\subsection{RQ 1: How is inclusive design taught to engineering design students?}

This research found that in most universities ID is taught as an all-inclusive topic within larger design modules throughout all year groups. Interview participants stated that ID was encouraged in all modules as "good design", suggesting it is a vital part of universities design philosophies, with three out of four universities delivering ID as part of other modules. This suggests that lecturers view ID as an integral part of the design process. However, student exposure to ID found to be varied, with class sizes varying from 20 to 120 students and students themselves reporting a spread of two to more than ten hours of ID teaching throughout their design education. The wide spread of class sizes may enable a wider coverage of students to be targeted, but with almost half of students receiving less than four hours ID learning in their overall design education, this raises questions on the depth of understanding students are able to gain in ID. This finds agreement with barriers identified within the literature Dong (2010) highlights that large class sizes create difficulty in teaching the fundamental ID principles. However, it should be noted that with ID integrated within other modules, delivery of the approach may not be fully recognised by students, resulting in the differing results between student and academic groups found here. This research recommends that more emphasis is place on ID to differentiate the approach from more generic design approaches to increase student awareness of the approach.

The institutions interviewed within this research highlighted a diverse range of content within ID lectures delivered. Some educators preferred to focus on the justification of the process and its benefits within a social and commercial context, whilst others focused on methods and tools. The survey results also highlighted the variety of ID methods and tools that students had experience with and indicated that educators place a higher importance on the qualitative methods and tools as opposed to the quantitative approaches - the Exclusion Calculator was the only quantitative ID tool discussed and was the least well known by the students. This is consistent with the findings from the interviews as lecturers felt they experienced limited benefit from quantitative ID methods. However, it is interesting that the number of responses for student familiarity with the Cambridge simulation glasses and gloves are low, as these were highlighted as one of the main assistive learning tools by educators during the interviews. This suggests there may be a lack of clarity within the teaching of ID. While many of the ID methods taught are also applicable to other user-centred design approaches (personas, observations and interviews), this research recommends that more emphasis is placed on how those methods could be utilised specifically in the context of ID to ensure student understanding of diverse user needs. It is also recommended that more time should be spent on ID focused methods and tools such as simulation gloves and glasses, as well as quantitative tools such as the Cambridge Exclusion Calculator.

When questioned about their knowledge of specific ID processes, the responses from students were evenly distributed $-43 \%$ of students claimed they had experience in using a specific ID process. 
However, this conflicts with findings from the literature review and interviews as there is little discussion of any specific ID processes being applied within education. The lecturers interviewed reported that none of their affiliated universities utilise a specific ID methodology when educating students, relying instead on a variety of generic applicable methods, with one participant identifying the IDEO method cards as a tool for guiding the ID process. This suggests a lack of clarity surrounding relevant ID methodologies in an educational context and leads to the recommendation that ID methods and processes are added to the curriculum to aid student implementation of ID methods in the design process.

The variation in responses from both students and academics suggests scope for improvement surrounding the communication of basic ID theory. Student responses indicate an understanding of user centred methods (observations, personas and interviews), but the lack of awareness of methods to specifically understand diverse user requirements suggests that students are struggling to differentiate ID from other user centred design approaches.

\subsection{RQ 2: Would a structured approach to inclusive design benefit the education of engineering design students?}

When questioned on the benefits of a more structured approach to ID, the results from the interviews and student survey presented an interesting contrast of opinions. The interviews conducted with design educators concluded that a more structured ID methodology would not bring benefit to the education of students. However, the interviews identified a need for greater structure within the design process to indicate where ID methods and tools should be utilised effectively.

The opinion of the students contrasted with those of the design educators. The majority of students (79\%) highlighted that a more structured methodology which identified where the ID methods and tools should be applied would be beneficial to their learning. This response suggests that more collaboration is required between design educators and students towards designing and delivering course content.

The contrast in feedback from design educators and students suggests that a more structured approach to ID may benefit student learning. The findings from the study suggest that lecturers may view ID as an integral part of good design practice, while students struggle to differentiate ID from other design approaches. Recommendations were made for a more structured ID framework, which indicates where ID methods and tools should be applied within the design process. This presents scope for future work to identify what the requirements for, and the development of, that framework.

\subsection{Recommendations}

This paper encourages collaboration between design students and educators when deciding upon course content, to ensure the material best reflects students' learning requirements. The following structure is proposed to ensure greater student understanding of ID and the use of its method and tools.

- ID should be taught in early years as a specific module - either stand-alone or as part of a wider user centred design module - to enhance student understanding and awareness of ID and clearly distinguish ID from other user centred approaches. Curriculums should emphasise the benefits, barriers and basic principles of ID.

- Early year ID modules should utilise a basic framework (e.g. the ID framework proposed by Wilson, 2017) to structure the class. An ID specific framework will encourage diversity of user in the design process, in addition to the use of appropriate tools and methods at relevant stages within the design process.

- Later years should encourage implementation of ID within industrial design projects, as an integral part of good design practice.

- In line with higher educator recommendations ID methods and tools should form part of a holistic user centred design approach without the need for a prescriptive framework in later years. In addition to the above approach, this paper also encourages transparency between universities to facilitate the sharing of successes and failures to further develop ID education and the development of a cohesive educational strategy pertaining to ID. 


\section{CONCLUSIONS}

This study aimed to understand the current approach to ID education within UK Higher Education Institutions. With the global social challenges associated with population ageing, in addition to a high percentage of the population experiencing some form of disability, it is vital that our designers are equipped to deal responsibly with the diverse capabilities these challenges bring. This study utilised interviews with design educators and a student survey to understand how ID is currently taught to engineering design students and whether a more structured approach to ID may be of benefit.

The focus of ID teaching varied between educational institutions - some focused on the justification of an ID process and its benefits within a social and commercial context, while others focused on ID methods and tools. It is noted that educators placed a higher importance on the qualitative methods and tools (i.e. simulation gloves) as opposed to the quantitative approaches (i.e. Exclusion Calculator). The research found mixed results between design educators and engineering design students: most interestingly that student familiarity with the Cambridge simulation glasses and gloves were low, despite these highlighted as one of the main assistive learning tools by design educators. Despite $43 \%$ of students claiming they had experience using a specific ID process, design educators reported that they did not teach a specific ID process. This research suggests there is a lack of clarity within the teaching of ID within UK Higher Education institutions. Recommendations are made in this paper to improve ID education and include that greater transparency should be encouraged between universities to encourage the development of a cohesive ID education strategy, in addition to the development of a framework to aid the implementation of appropriate ID methods and tools within the design process. Future work will look to review the recommendations made in this paper with both lecturers and students to further refine these guidelines into an established approach.

\section{REFERENCES}

Bloom, D. E., Canning, D. and Lubet, A. (2015), “Global Population Aging: Facts, Challenges, Solutions and Perspectives", Journal of the American Academy of Arts and Sciences, Vol. 144 No. 2, pp. 80-92. https://doi.org/10.1162/DAED_a_00332

Bouma, H. (2013), “Accommodating older people at work”, Journal of Gerontechnology, Vol. 11 No. 4, pp. 489-492. https://doi.org/10.4017/gt.2013.11.4.001.00

Carse, B., Thomson, A. and Stansfield, B. (2010), "Use of biomechanical data in the inclusive design process: Packaging design and the older adult”, Journal of Engineering Design, Vol. 21 No. 2-3, pp. 289-303.

Carter, H. (2014), "Whose responsibility is inclusive design?", [Online] Available at: www.designcouncil.org.uk/news-opinion/whose-responsibility-inclusive-design [Accessed 3.12.2015]

Clarkson, P. J. and Coleman, R. (2015), "History of inclusive design in the UK", Applied Ergonomics, Vol. 46, pp. 235-247. https://doi.org/10.1016/j.apergo.2013.03.002

Cremers, A. H., Neerincx, M. A. and Jong, J. G. D. (2013), "Inclusive design: bridging theory and practice", International Conference on Engineering Psychology and Cognitive Ergonomics (EPCE 2013), Berlin, Springer pp. 323-332. https://doi.org/10.1007/978-3-642-39354-9_35

Cremers, A. H., Jansen, Y. J. F. M., Neerincx, M. A., Schouten, D. and Kayal, A. (2014), "Inclusive design and anthropological methods to create technological support for societal inclusion", Universal Access in Human-Computer Interaction - Design and Development Methods for Universal Access (UAHCI 2014), pp. 31-42. https://doi.org/10.1007/978-3-319-07437-5_4

Design Council (2008), "Design Council". [Online] Available at: www.designcouncil.info/inclusivedesignresource [Accessed 8.11.2015]

Dong, H. (2010), "Strategies for teaching inclusive design", Journal of Engineering Design, Vol. 21 No. 2, pp. 237-251. https://doi.org/10.1080/09544820903262330

Dong, H., McGinley, C., Nickpour, F. and Ciffer, A. S. (2015), "Designing for designers: Insights into the knowledge users of inclusive design”, Applied Ergonomics, Vol. 46, pp. 284-291. https://doi.org/10.1016/j.apergo.2013.03.003

Dong, H., Clarkson, P. J. and Ahmed, S. (2004a) "Investigating the perceptions of manufacturers and retailers to inclusive design”, The Design Journal, Vol. 7 No. 3, pp. 3-15. https://doi.org/10.2752/146069204789338398

Dong, H., Keates, S. and Clarkson, P. J. (2004b) "Inclusive design in industry: barriers, drivers and the business case", User-centred interaction paradigms for universal access in the information society, pp. 305-319. https://doi.org/10.1007/978-3-540-30111-0_26

Easterby-Smith, M., Thorpe, R. and Jackson, P. (2012), Management Research. 4th Edition, London, SAGE. 
Goodman-Deane, J., Langdon, P. and Clarkson, P. J. (2010), "Key influences on the user-centred design process", Journal of Engineering Design, Vol. 21 No. 2-3, pp. 345-373. https://doi.org/10.1080/09544820903364912

Herriott, R. and Jensen, B. G. (2013), “Student's responses to inclusive design”, Design Studies, Vol. 34 No. 4 , pp. 4438-4453. https://doi.org/10.1016/j.destud.2013.01.005

Johnson, D., Clarkson, J. and Huppert, F. (2010), “Capability measurement for inclusive design”, Journal of Engineering Design, Vol. 21 No. 2-3, pp. 275-288. https://doi.org/10.1080/09544820903303464

Keates, S., Clarkson, P. J., Harrison, L. A. and Robinson, P. (2000), "Towards a practical inclusive design approach", Proceedings on the 2000 conference on universal usability, pp. 45-52.

Langdon, P., Johnson, D., Huppert, F. and Clarkson, P. J. (2015), “A framework for collecting inclusive design data for the UK population", Applied Ergonomics, Vol. 46, pp. 318-324. https://doi.org/10.1016/j.apergo.2013.03.011

MacDonald, A. (2006), “The inclusive deign challenge: a multi-disciplinary educational approach", Designing Accessible Technology. London, Springer, pp. 3-12.

Reed, D. and Monk, A. (2011), "Inclusive design: beyond capabilities towards context of use", Universal access in the information society, Vol. 10 No. 3, pp. 295-305. https://doi.org/10.1007/s10209-010-0206-8

Sims, R. (2003), "Design for all: methods and data to support designers”, Loughborough University, PhD Thesis.

United Nations (2015), “World Population Ageing”, New York: Department of Economic and Social Affairs Population Division.

University of Cambridge (2013), "Inclusive design toolkit", [Online] Available at: http://www.inclusivedesigntoolkit.com/betterdesign2/ [Accessed 31.03.2015].

Vavik, T. (2011), "Strategies for teaching universal design", Proceedings of E and PDE 2011, the 13th International Conference on Engineering and Product Design Education, London, pp. 360-365.

Vavik, T. and Keitsch, M. M. (2010), "Exploring relationships between universal design and social sustainable development: some methodological aspects to the debate on the sciences of sustainability", Sustainable development, Vol. 18 No. 5, pp. 295-305. https://doi.org/10.1002/sd.480

Waller, S., Bradley, M., Hosking, I. and Clarkson, P. J. (2015), "Making the case for inclusive design", Applied Ergonomics, Vol. 46, pp. 297-303

Wilson, N. (2017), "Capturing the sports design process to facilitate the uptake of inclusive design", $\mathrm{PhD}$ Thesis, University of Strathclyde, Glasgow.

Wilson, N., Thomson, A., and Riches, P. (2017), "Improving inclusive design practice - transferring knowledge from sports design practice", International Conference on Engineering Design 2017, Vancouver, Canada.

World Health Organisation (2011), "World Report on Disability - Summary”, Geneva, Switzerland. 